\section{Gastric cancer}

\author{
P McCulloch
}

I think I am going to like Japan. In my first two days here I have already received more overt kindness and generosity than I would be likely to get in Scotland in a month of our Presbyterian Sundays. Both my host and his senior colleagues have spent hours ensuring that my most trivial need is attended to. Some of this attention has been positively embarrassing, as when my host spent 20 minutes out of a busy day selecting and ordering a chair for me. Other people have been utterly delightful, like the two charming secretaries from the office of the foundation that is supporting my visit who insisted on coming out to my new apartment, checking it out, then introducing me to real Japanese food, before returning late to their office to catch up with the work I had interrupted. My appallingly mangled odd words of Japanese are picked up with well feigned astonishment by all and receive compliments far beyond their deserts-I would suspect gentle leg pulling anywhere else, but the Japanese do not seem to be strong on the concept of leg pulling.

When I began to get interested in stomach cancer my friends advised me to reconsider, preferably after an appropriate course of counselling or behavioural therapy. But I had just got a lecturer's post with the coveted senior registrar status and I was keen to define my clinical self in terms that I was happy with for the future. My curriculum vitae was strong on breast cancer, but I was looking for an alternative oncological interest that offered more technical challenges. Reading the literature from the past two decades, I became fascinated by the amazing contrast between the nihilism, gloom, and despondency that envelop the subject in the West and the confidence and enthusiasm emanating from Japan. There seemed to be an almost complete barrier of incomprehension and positive disbelief between the two camps. When I read the Japanese descriptions of their radical gastrectomy techniques the effect was similar to that of reading instructions with flat pack furniture: the words are English, but what do they really mean? A certain personal contrariness attracted me to the idea of going East to further my career instead of West, and so began a two year correspondence with Dr Mitsuru Sasako, of the National Cancer Center Hospital in Tokyo. It was his invitation which eventually led to my recent bemused arrival at Narita airport, at the start of a four month stay, which I hope will let me really evaluate the Japanese approach and its potential value in the West.

\section{Ward rounds}

Ward rounds on my first day were a strange experience. There seem to be scores of nurses in the ward, but only one comes on the round and her only function is to staff the dressings trolley. Examining and changing the dressings on each wound seems to be the main activity on the round and is done by the medical staff, usually by the consultant concerned. Every wound is religiously swabbed with iodine tincture, although there was not a sign of infection anywhere and some of the wounds were as much as two weeks old. The resident staff must keep a close but unobtrusive eye on the patients' condition between rounds, as

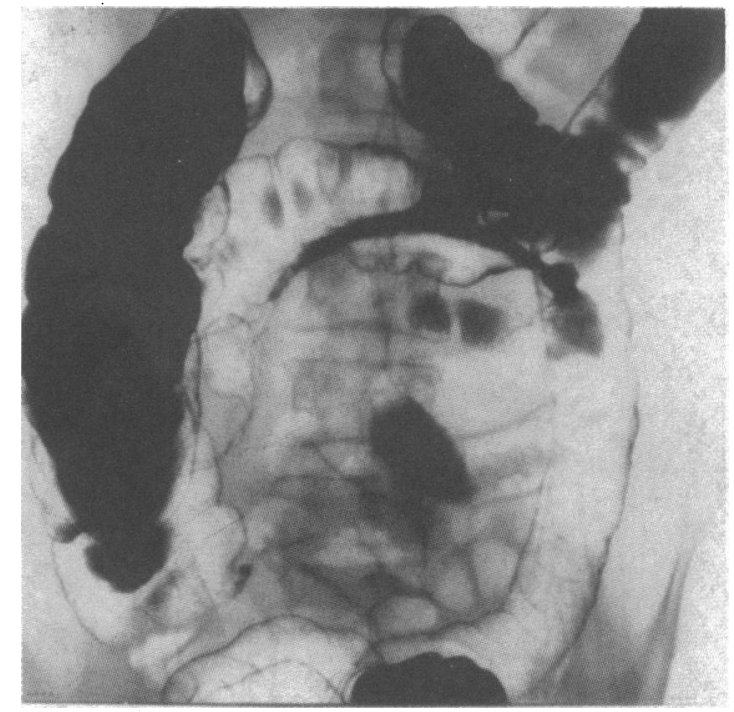

Posterior wall of abdomen after fapanese extended lymph node dissection

things like drainage amounts, fluid balance, and temperature are rarely overtly inquired about on the rounds; nor are the laboratory results discussed at the bedside.

In fact, the acute hypertrophy of the medical entourage makes it difficult for anything to be discussed at the bedside. Usually two of the three consultants on the firm attend the round, together with the chief resident and two more junior residents (residents are equivalent of British registrars). In addition to these people there are visitors from the four points of the compass: today's round had one representative each from Scotland (myself), England, China, Korea, Poland, Saudi Arabia, and Peru. For us, as for all concerned, the value of the event was symbolic rather than practical. By being there we demonstrated our commitment.

\section{Anaesthetics}

The behaviour of the anaesthetists here is extremely unobtrusive. They use epidural morphine for postoperative pain relief in all gastric surgery; the incision is usually up to at least the T6 dermatome, so the control of respiratory function must be finely judged. As with fluid and electrolyte control no overt fuss is made over monitoring this, and postoperative respiratory function is clearly regarded as a routine matter not expected to give problems. All the anaesthetists in the theatres I have been in are residents and most are passing through on a path to a surgical career. They are supervised by one or two consultants who circulate through the suite of eight theatres. This may explain why they have yet to utter one word between them, and why the relation between surgeon and anaesthetist seems so harmonious. It is the custom here for the surgical team to wait with patients until they regain consciousness, a tradition apparently dating from the times when the surgical staff also attended to all the anaesthesia. Another interesting customary practice is for the surgeon to discuss the operation immediately 
with an assembly of relatives of the patient gathered outside the theatre suite, and to show them the dissected specimen of the resected organ.

\section{Harmony in theatre}

The working atmosphere in theatre seems extremely pleasant here. The roles of the operator, first and second assistant, scrub nurse, and floor nurse are all very clearly defined and much as I expected, but prejudices built up in Britain made me expect a tense, formal atmosphere of barked commands and anxious submissiveness. In fact there is a good deal of good natured backchat between the surgeons and the nurses, and no evidence of the strained relationships and unspoken resentments which all too often mar relations in theatres at home. Certainly everyone knows their place, but equally no one seems to feel undervalued, threatened, resentful, envious, or contemptuous. If this is social rigidity, there is a lot to be said for it. There is no prima donna consultant shouting the odds, no clash with proud, fiercely defensive theatre sisters, and no evidence of biting sarcasm in either direction across the "blood-brain barrier" at the top of the table. Sadly, I doubt if Japanese working practices are any easier to export in medicine than in business.

\section{Japanese gastrectomy}

I went to theatre today to assist at a subtotal gastrectomy for gastric cancer. The operation took about four and a half hours and by the end I was stiff, tired, hungry - and very impressed. The standard of surgical technique here is an order of magnitude better than is customary in Britain. I had had discussions before coming here about the different biological nature of gastric cancer in Japan and about the technically ideal nature of the Japanese patient, with long mesenteries and very little fat. There is some truth in the second comment (the first being essentially undisprovable), but I have to say that I now regard it largely as an excuse. In today's gastrectomy the surgeon began by kocherising the duodenum right off the vena cava and then cleared the lymphatics and fatty tissue off the front and sides of the cava and aorta and in between them from the level of the inferior mesenteric artery up to the origin of the superior mesenteric artery. He calmly and methodically displayed, dissected, and stripped each structure in that spaghetti

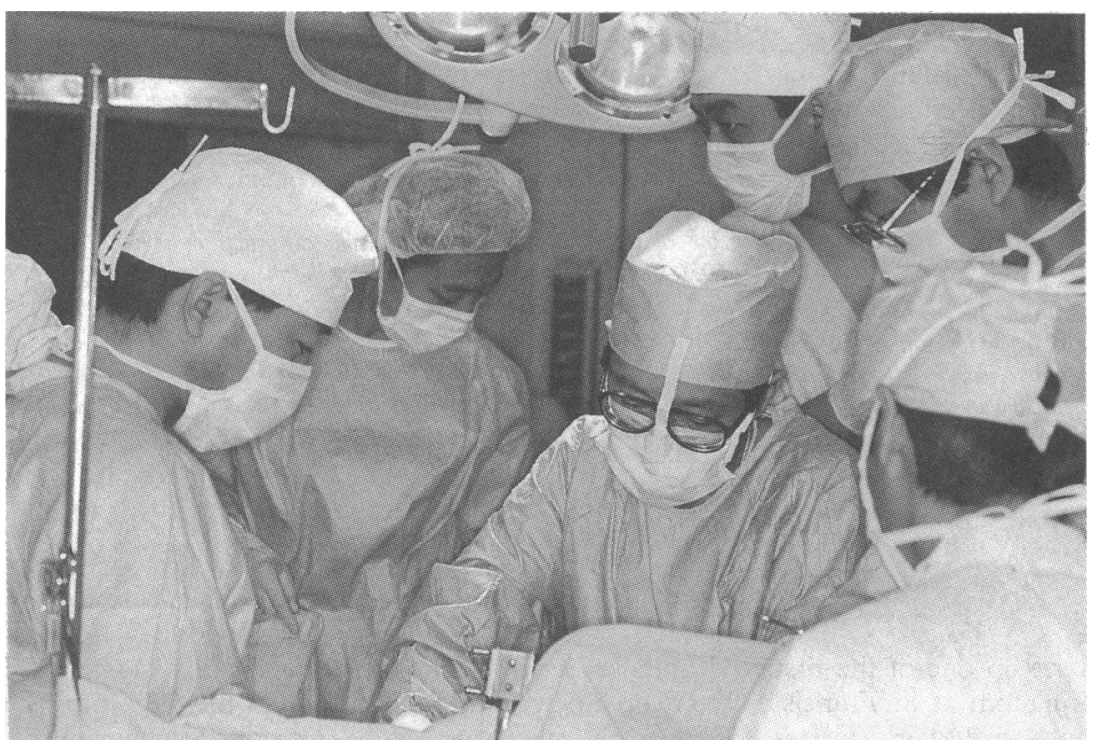

The atmosphere in Fapanese theatres lacks the formal stiffness in British ones junction of renal, hemiazygous, mesenteric, and lumbar vessels, and when he had finished the vascular structures were displayed against a background of anterior spinal ligament. He mobilised the pancreas and spleen right out of the abdomen with equal sangfroid, preserving both while picking out all the lymph nodes and fat surrounding the friable veins for histological examination. He then picked the coeliac axis and portal triad as clean as bones in the desert. It is difficult to be sure about the importance of biological differences in our two nations in determining survival from gastric cancer, when such a large difference in practice is evident. We do a radical gastrectomy for gastric cancer in those (regrettably few) cases in which there is no obvious distant metastasis: so do the Japanese. But from what I have seen ours is a 1940 s version to their 1990 s one.

\section{Communication}

The Japanese are rather funny about their language: they enjoy sympathising with a struggling foreigner about how difficult it is but seem unable to help very much. Requests to speak very slowly are usually ignored or else only the words that are completely clear already are slowed down-the awkward phrase you couldn't get the first time being produced with the same triumphal flourish in the revised version. The main difficulty is in fact the completely unfamiliar structure of the grammar, the words themselves being quite easy to pronounce. A nasty surprise has been the realisation that my brain has now reached the stage where it really ought to undergo an MOT of some kind and that my difficulties with Japanese vocabulary cannot really be blamed on the language.

Japanese writing, on the other hand, is certainly the most difficult in the world. It comprises a Chinese derived pictogram alphabet, Kanji and two indigenous phonetic alphabets (Katakana and Hiragana). The three alphabets are all mixed up together, the characters used for a word usually depending on whether it is originally Chinese, Western, or indigenous. Few concessions are made to foreigners, and even prices are often written in Japanese. This had the effect of making me suddenly aware of what it is to be totally illiterate. Walking through a veritable ocean of meaningless signs and symbols on buildings, in newspapers, on articles in shops, even, frustratingly, on home equipment like the washing machine and air conditioning unit, I quickly developed a sense of inadequacy amounting almost to paranoia. On the wards, the notes are handwritten in Kanji. The very limited information that can be deduced from numbers and diagrams leaves me with the feeling that perhaps my colleagues' handwriting is not so incomprehensible after all.

Even numbers presented me with some problems. Interested in the relative ages of patients with gastric cancer in Britain and Japan, I worked out the ages of all the patients on the ward from their recorded dates of birth. I was surprised by some of the figures I got, with some very young looking patients being, apparently, in their 90s while one or two old timers turned out to be in their 'teens. All was eventually made clear. For some purposes (which?) the Japanese use an old calendar in which the date is calculated from the year of the reign of the Emperor. Thus, an old man born in 1907 would have a recorded birth year of $30 \mathrm{Meiji}$ (the name for the years of the reign of Hirohito's grandfather). I suppose that, like cricket, it's really quite straightforward if you start young.

(Accepted 11 November 1991) 